І. Ш. Невлюдов, Б. О. Малик, О. В. Токарєва, В. В. Невлюдова

Харківський національний університет радіоелектроніки, Харків, Україна

\title{
ПІДВИЩЕННЯ ЕФЕКТИВНОСТІ ОПТОВОЛОКОННИХ КАНАЛІВ ЗВ’ЯЗКУ
}

\begin{abstract}
Анотація. Волоконно-оптичні системи є одним з найбільш перспективних напрямків при розробці фізичної основи інформаційного простору. При реалізації оптоволоконних ліній зв'язку часто виникає необхідність узгодження оптоелектронних компонентів з різними поперечними перетинами випромінюючих і приймаючих областей і різними числовими апертурами. Варіантом такого завдання може бути з'єднання одномодового і багатомодового волокон або випромінювачів і фотоприймачів 3 волокнами різних типів. Одним з методів такого узгодження є створення каскадних волокон, в яких лінзове волокно і кілька ділянок градієнтних волокон інтегровано в одномодове волокно. Предметом дослідження $\epsilon$ технології елементів волоконно-оптичних систем передачі. Метою даної роботи є створення компонентів волоконно-оптичних ліній зв'язку, що дозволяють підвищувати ефективність вводу випромінювання від джерела в оптичних світловод, зокрема одномодовий. Для досягнення поставленої мети необхідно вирішення наступних завдань: розглянути фактори, що впливають на втрати енергії при генерації і вводу випромінювання джерела в оптичне волокно, а також розробити і впровадити систему узгоджуючих елементів і дати послідовність дій для ефективного вводу випромінювання джерела в одномодове волокно. Висновки. Запропонована технічна і технологічна реалізація процесу робить можливим вводити більшу потужність в оптоелектронні лінії передачі інформації, що підвищує ефективність вводу випромінювання до 20 дБ. Визначення точності розташування сполучної площини в пристроях узгодження та взаємного розміщення випромінювачів та оптичного волокна дає можливість знизити втрати в з'єднанні до 0,1 дБ, передавати інформацію з більшою надійністю на більші відстані без регенерації і зберегти працездатність волоконно-оптичної системи в умовах впливу механічних, кліматичних і радіаційних факторів.
\end{abstract}

Ключов і слов а: оптичне волокно; випромінювач; потужність; ефективність передачі.

\section{Вступ}

Для підвищення ефективності оптоволоконних ліній передачі необхідно компенсувати втрати оптичної енергії шляхом підвищення потужності генераторів, чутливості приймачів, підвищення ефективності вводу випромінювання високопотужних джерел в оптичне волокно, особливо одномодове, збільшення відношення сигнал/завада. Необхідно оптимізувати теоретично обгрунтовані втрати шляхом розрахунку взаємодії випромінювання з матеріалами і конструкціями оптичних волокон [1-3].

\section{Теоретичне обгрунтування}

Коефіцієнт вводу випромінювання в волокно обмежується такими факторами (рис. 1):

- обмеженням поверхневого припустимого кута Өкр внутрішнім поверхневим відбиттям;

- Френелівське відображення від поверхні розділу повітря - напівпровідник;

- поглинанням поміж точкою генерації випромінювання та випромінюючою поверхнею: фотон 3 енергією, більшою за ширину забороненої зони $E_{g}$ може збудити електрон у зоні провідності, при цьому фотон самопоглинається.

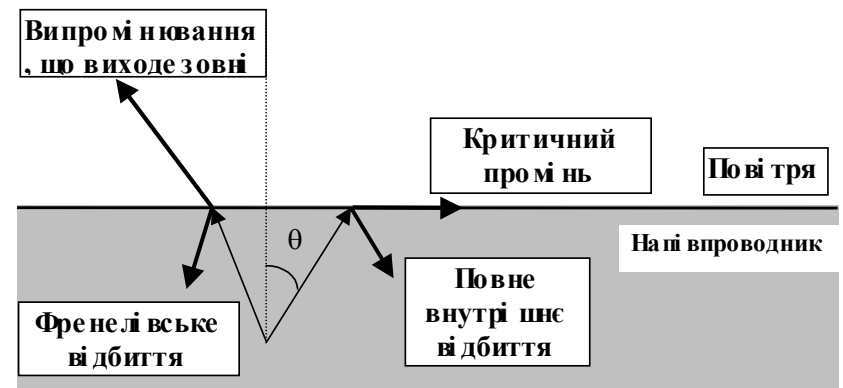

Рис. 1. Світловий потік джерела випромінювання
Отже, відстань до поверхні має бути скорочена, однак біля поверхні багато вільних «пасткових» рівнів, які змінюють безвипромінювальний час життя та знижують внутрішню квантову ефективність.

Світловий потік визначається інтегруванням потужності, що випромінюється в одиницю тілесного кута в напрямку під кутом $\theta$ до нормалі до його поверхні $I=I_{0} \cos \theta$ :

$$
\Phi_{0}=\int_{\theta=0}^{\pi / 2} I_{0} \cos \theta \cdot 2 \pi \cdot \sin \theta d \theta=\pi I_{0} .
$$

Частина світлового потоку джерела випромінювання, що потрапляє в оптичне волокно обмежена числовою апертурою волокна $N A=\sin \phi_{\kappa p}$ та визначається інтегралом:

$$
\Phi=\int_{0}^{\phi_{k p}} I_{0} \cos \theta \cdot 2 \pi \cdot \sin \theta d \theta=\pi I_{0} \sin ^{2} \phi_{\kappa p}=\Phi_{0} \cdot N A^{2}
$$

де $\varphi_{\kappa p}$ - апертурний кут волокна.

Отже, ефективність вводу у волокно дорівнює

$$
\Phi / \Phi_{0}=N A^{2} .
$$

Коефіцієнт ефективності виводу випромінювання $з$ джерела з урахуванням критичного кута $\theta_{c}$.

Світловий потік випромінювання в одиничному куті у напрямку $\theta$ відносно нормалі до поверхні:

$$
\Phi_{\mathrm{o}}=2 \int_{\theta=0}^{\pi / 2} I_{o} \cos \theta \cdot 2 \pi \cdot \sin \theta d \theta=2 \pi I_{o}
$$

Доля загальної потужності, обмежена кутом $\theta c$.

$$
f=\frac{1}{2 \pi I_{0}} \int_{0}^{\theta_{c}} I_{0} \cos \theta \cdot 2 \pi \cdot \sin \theta d \theta=\frac{1}{2} \sin ^{2} \theta_{c}=\frac{n_{0}^{2}}{2 n^{2}} .
$$


Якщо розглянути приклад використання для випромінювача арсеніду галію при $n=3,7$ та $n_{0}=1$ $\boldsymbol{f}=0,036$ то при малих $\theta<\theta c$ за рахунок Френелівського відбиття частина енергії $R$ відбивається, отже при перпендикулярному падінні проходить частина $t$.

$$
t=1-R=4 n_{0} n /\left(n_{0}+n\right)^{2}=4 n /(1+n)^{2},
$$

якщо $n_{0}=1$. При більш похилих променях частина енергії що випромінюється, змінюється мало і дорівнює нулю, якщо $\theta c=0$. Отже, коефіцієнт ефективності виводу за рахунок Френелівського обмеження для GaAs $t=0,67$. Цей коефіцієнт може бути збільшений за рахунок просвітлення, при цьому ідеальне значення дорівнює $\left(n_{0} n\right)^{1 / 2}$ коли $t$ прямує до 1 . Просвітлення зазвичай виконується такими матеріалами:

- корунд $n=1,76$;

- окисел кремнію $n=1,9$;

- нітрид кремнію $n=2,0$.

Загальний коефіцієнт передачі має вираз:

$$
f \cdot t=2 / n(1+n)^{2}=0,24 .
$$

Отже, ефективність виводу випромінювання за межі кристала джерела (зовнішня квантова ефективність):

$$
\eta_{\text {зовн }}=\eta_{\text {внутр }} \cdot f \cdot t,
$$

а ефективність вводу у волокно:

$$
\eta_{\text {вол }}=\eta_{\text {зовн }} \cdot N A^{2} \text {. }
$$

$\eta_{\text {вол }}$ для волокна с $N A=0,17$, джерела GaAs 3 $f \cdot t=0,024$ та $\eta_{\text {внутр }}=0,5$ становить $\eta_{\text {вол }}=0,00035$.

Загальна потужність, яка генерується в джерелі випромінювання:

$$
\Phi_{\text {внутр }}=\eta_{\text {зовн }} \cdot e^{-1} \cdot E_{\text {фотона }}
$$

при струмі $I=100 \mathrm{MA}$, енергії фотона $E_{\text {фотона }}=1,4 \mathrm{eB}$, $\Phi_{\text {внутр }}=70 \mathrm{MBm}$, а оптична потужність, яка випромінюється у повітря:

$$
\Phi_{\text {пов }}=\eta_{\text {зовн. }} \cdot e^{-1} \cdot E_{\text {фотона }}=1,74 \mathrm{MBm},
$$

де $\eta_{\text {зовн }}=\eta_{\text {внутр }} \cdot f \cdot t$.

Потужність, яка потрапляє в оптичне волокно:

$$
\Phi_{\text {вол }}=\eta_{\text {вол }} \cdot e^{-1} \cdot E_{\text {фотона }}=49_{\text {мкВm, }}
$$

де $\eta_{\text {вол }}=\eta_{\text {зовн }} \cdot N A^{2}$.

\section{Експериментальне впровадження}

При реалізації оптоволоконних ліній зв'язку часто виникає завдання узгодження оптоелектронних компонентів і волокон з різними поперечними перетинами випромінюючої і приймаючої області та різними числовими апертурами. Варіантом такого завдання може бути з'єднання одномодового і багатомодового волокон або випромінювачів і фотоприймачів з волокнами різних типів $[4,5]$.

Наприклад, при використанні лазерного діода для передачі великої потужності через одномодове волокно необхідне узгодження полів, що генеруються діодом і виникають в пов'язаному з ним одномодовому волокні. Доводиться погоджувати параметри електромагнітних коливань i, отже, геометричних параметрів елементів. Одним 3 варіантів системи для узгодження полів можуть бути волокна, в яких приймальне волокно спеціальної форми і ділянки градієнтних багатомодових волокон інтегровані в одномодове волокно [7-9]. При виготовленні узгоджуючої секції у вигляді клиноподібного багатомодового оптичного волокна послідовно зрощують два відрізки багатомодових градієнтних оптичних світловодів і одномодового волоконного світловоду $[2,6]$.

В даний час втрати при з'єднанні можуть становити 0,03 дБ. Для знаходження сполучної площині в волокні необхідно використовувати мікроскопи 3 високою роздільною здатністю. Для оцінки місця розташування сполучної площині спостереження проводяться під мікроскопом зі збільшенням 360X. Однак відстань між волокном і об'єктивом в мікроскопах з високою роздільною здатністю дуже мала.

У виробництві каскадного волокна, процедура сколювання вимагає великого простору, в якому відстань між волокном і лінзою пристрою контролю повинно бути більше 4 см. Отже, метод визначення положення сполучної площини з великою робочою відстанню (> 40 мм) і з низьким збільшенням $(<8 \mathrm{X})$ контрольної системи є ключем до поліпшення процесу виготовлення каскадних волокон [2].

Запропонований метод контролю дозволяє здійснити знаходження положення сполучної площини. Для спостереження використовується непрямий метод із застосуванням явища інтерференції для визначення площини з'єднання. Наступні розрахунки і моделювання дозволяють ідентифікувати місце розташування стику. В реальності темні лінії при проходженні світла через багатомодове волокно складають близько 3 мкм, що залежить від площини фокусування і розташування, а темні лінії при проходженні світла через одномодове волокно, як правило, становлять близько 1 мкм. Таким чином, можна просто використовувати темні лінії, щоб визначити сполучну площину, якщо дозвіл контрольного обладнання більше ширини темної лінії в 1 мкм. Як правило, ПЗС-датчики 3 8-кратним збільшенням лінзи можуть мати дозвіл зображення вище, ніж 1 мкм. Цього достатньо для контролю.

При великих робочих відстанях контролю явище світлової інтерференції впливає на зображення, що робить спостереження темних ліній скрутним. Інтенсивності і кількість інтерференційних смуг в цих двох секціях волокна будуть різними. Таким чином, сполучну площину можна знайти шляхом спостереження істотних відмінностей в інтерференції між двома ділянками волокна (рис. 2).

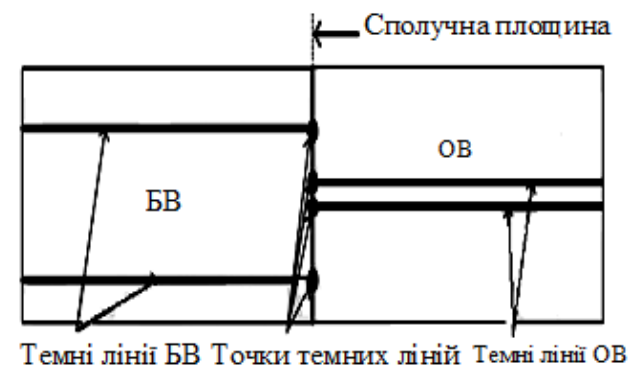

Рис. 2. Темні лінії в одномодовому і багатомодовому волокнах для визначення сполучної площин 
Інтерференційна картина моделюється на основі параметрів інтерференційних смуг [9]. Для знаходження положення смуг використовується метод трасування променів. Всі промені світла починаються з однієї початкової площини і, нарешті, досягають фокальній площини. Після виходу з освітлювача, промені світла будуть паралельними, поки вони не торкнуться зовнішнього краю волокна.

Геометричні розміри узгоджуючих елементів та їх взаємне розміщення підтримуються при виготовленні та експлуатації. При потребі визначення і забезпечення розмірів окремих складових узгоджуючого пристрою та їх взаємне розміщення (з точністю до мікрометрів) пропонуються шляхи досягнення такої точності і технологія виготовлення пристрою в цілому.

Виготовлення узгоджуючої секції оптичного волокна [10], полягає в тому, що у клиноподібного багатомодового оптичного волокна, яке отримують послідовно зрощуючи два відрізки багатомодових градієнтних оптичних світловодів різних видів і одномодового волоконного світловоду визначають межу розділення між різними ділянками з'єднаних оптичних волокон. Цю межу визначають за допомогою проекції на двохкоординатний фотоелектричний прилад зображення картини, що являє собою суперпозицію електромагнітних хвиль оптичного діапазону. Картина утворюються при проходженні через оптичні волокна паралельних світлових променів, які взаємодіють між собою. Така картина однозначно відображає розподіл енергії відповідно до оптичних та геометричних параметрів волокон. Після цього сигнал з фотоелектричного приладу у вигляді матриці значень сигналу з кожного елементу приладу опрацьовують для визначення межі розділу між волокнами.

Після визначення місця розподілу між волокнами та утворення наскрізного сколу, зазвичай, не визначається відносне положення джерела випромінювання і узгоджуючої секції, яке забезпечує максимальну кількість енергії, що передається від джерела в лінію передачі.

Для оптимізації коефіцієнту передачі необхідно вирішити задачу визначення відносного положення джерела випромінювання (наприклад напівпровідникового лазера) i узгоджуючої секції, яке забезпечує максимальну кількість енергії, що передається від джерела в лінію передачі. Завдяки тому, що на вхід узгоджуючої секції подається оптичне випромінювання від джерела випромінювання, що може переміщатися на однаковій відстані по координатах. Визначення оптимального відносного положення джерела і узгоджуючої секції забезпечує максимальну кількість енергії, що передається від джерела в лінію передачі.

Технологічно узгодження можна реалізувати наступним чином. Після визначення місця з'єднання відрізків оптичних волокон 1-БГС1та 2 - БГС2 (рис. 3) (наприклад, за допомогою зварювання) утворюють наскрізний скол для подальшого з'єднання 3 3- ОВС. На вхід узгоджуючої секції подається оптичне випромінювання (наприклад напівпровідникового лазера) 4, який може переміщатися на однаковій відстані (R) по координаті в площині p-n переходу (рис. 4, a), в перпендикулярній площині p-n переходу на відстані (R) (рис. 4, б), а також при переміщенні джерела випромінювання по відстані (L) в площині p-n переходу (рис. 4, в). При цьому визначається відносне положення джерела випромінювання і узгоджуючої секції, яке забезпечує максимальну кількість енергії, що передається в лінію передачі. Джерело випромінювання 4 переміщається відносно узгоджуючої секції з допомогою приводу 5 та трьохкоординатного столу 6. Інформація з фотоприймача 7 опрацьовується мікроконтролером 8, який керує приводом переміщення джерела випромінювання та вираховує оптимальне відносне положення джерела випромінювання та узгоджуючої секції [12-14].

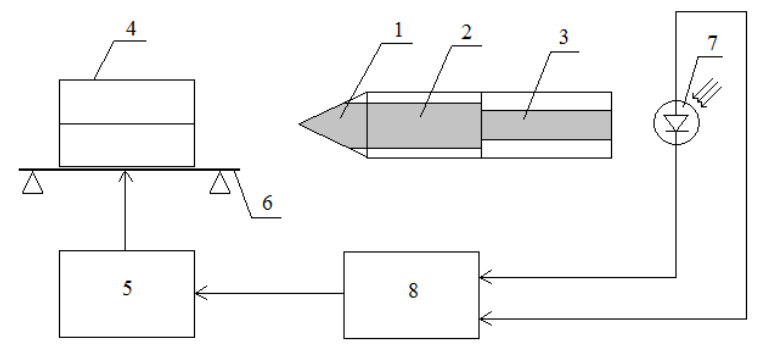

Рис. 3. Визначення місця з'єднання відрізків оптичних волокон

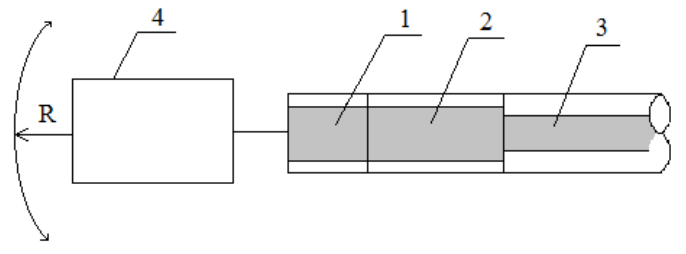

a - переміщення в площині p-n переходу

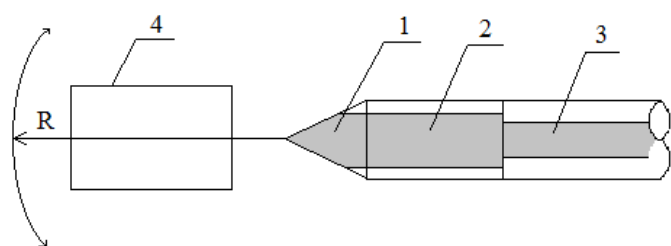

б - переміщення в перпендикулярній площині pn переходу

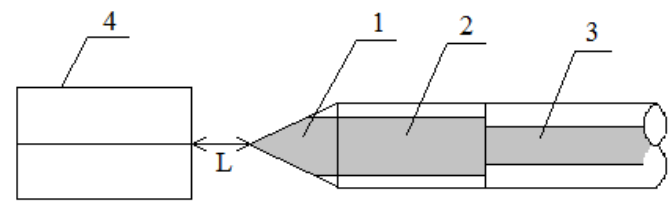

в - переміщення по відстані

Рис. 4. Визначення відносного положення джерела випромінювання і узгоджуючої секції

\section{Висновки}

В представленій роботі проведено дослідження технології елементів волоконно-оптичних систем передачі, а саме створення компонентів волоконнооптичних ліній зв'язку, що дозволяють підвищити ефективність вводу випромінювання від джерела в оптичних світловод, зокрема одномодовий. Було розглянуто фактори, що впливають на втрати енергії при генерації і вводу випромінювання джерела в оптичне волокно, а також розроблено і впроваджено 
систему узгоджуючих елементів. Надано послідовність дій для ефективного вводу випромінювання джерела в одномодове волокно.

При виконанні роботи досліджено фактори, що впливають на параметри вводу випромінювання в волокно та запропоновано конструкцію резонансної системи для формування потоку електромагнітного випромінювання найбільш придатного для вводу в одномодове волокно, а також запропоновано послідовність дій для визначення найкращого взаєморозташування випромінювача та волокна.

В роботі обгрунтовано використання методу підвищення ефективності вводу випромінювання потужних джерел в оптичні волокна. Запропонована технічна і технологічна реалізація процесу робить можливим вводити більшу потужність в оптоелектронні лінії передачі інформації, що підвищує ефективність вводу випромінювання до 20 дБ.

Окрім вищенаведеного варто відзначити, що визначення точності розташування сполучної площини в пристроях узгодження та взаємного розміщення випромінювачів та оптичного волокна дає можливість, в даний час, знизити втрати в з'єднанні до 0,1 дБ і передавати інформацію з більшою надійністю на більші відстані без регенерації. Це, в свою чергу, дасть змогу зберегти працездатність волоконно-оптичної системи в умовах впливу механічних, кліматичних і радіаційних факторів.

\title{
СПИСОК ЛІТЕРАТУРИ
}

1. Pachnicke S. Fiber-Optic Transmission Networks. Springer-Verlag Berlin Heidelberg, 2012.

2. Govind P. Agrawal. Fiber-Optic Communications Systems, Third Edition. John Wiley \& Sons, Inc, 2002.

3. Ivanov A. Fiber Optics: Components, Communications Systems, Measurements. M.: Syrus Systems, 1999.

4. Косенко В.В., Кучук Н.Г. Моделювання технічної структури інформаційно-телекомунікаційної мережі на основі конкретної реалізації інформаційної структури. Системи обробки інформащії. 2016. Вип.9 (146). С. 167-171.

5. Косенко В.В., Артюх Р.В., Роговой А.И. Вариантный синтез иерархии структур инфокоммуникационной сети. Системи управління навігації та зв'язку. Полтава. 2017. Випуск 4 (44). С. 60-63.

6. Bass M., Van Stryland E.W. Fiber Optics Handbook: Fiber, Devices, and Systems for Optical Communications. McGrawHill Professional, 2002.

7. Patent G02B 6/22 "Monomode Optical Fibre', 2001.

8. H. Yoda, T. Endo, and K. Shiraishi "Cascaded GI-fiber chips with a wedge-shaped end for the coupling between an SMF and a high-power LD with large astigmatism," in J. Lightw. Technol, vol. 20, no. 8, 2002, pp. 1545-1548.

9. Филипенко, А.И., Малик Б.А., Селенкова Н.П., Гончар В.В. Контроль геометрических параметров каскадных оптоволоконных структур. Восточно-Европейский журнал передовых технологий. 2012. №3/5(57). С.28-31.

10. I Sh Nevliudov, AI Filipenko Method of the Interferential Images Analysis During Testing of Quality Parameters of FiberOptical Components Surface / News of Engineering Sciences Academy of Ukraine: Mechanical engineering and progressive technologies, 2004, № 24, p. 81-87

11. И.Ш. Невлюдов, А.И. Филипенко, Б.А. Малик Методология и оборудование контроля параметров компонентов волоконно-оптических систем передачи информации / Прикладная радиоэлектроника: сб. АН Прикладной радиоэлектроники, 2002, №1. - с. 51-56.

12. B. Malyk, O. Tokarieva, S. Malyk-Zamorii "Optical fiber structures performance enhancement under the conditions of ionizing radiation high power levels," in Problems of Atomic Science and Technology, no. 2 (114), 2018, pp. 13-18.

13. Patent UA115811 "Method for optical fibers matching section manufacturing", 2017.

14. Patent UA122687 "Method for optical fibers matching section manufacturing", 2018.

Received (Надійшла) 22.01.2020

Accepted for publication (Прийнята до друку) 12.02.2020

\section{Increasing the efficiency of fiber optic communication channels}

\author{
I. Nevlyudov, B. Malik, O. Tokareva, V. Nevlyudova
}

Abstract. Fiber optic systems are one of the most promising areas in the development of the physical basis of the information space. When implementing fiber-optic communication lines, it is often necessary to match the optoelectronic components with different cross sections of the emitting and receiving regions and various numerical apertures. A variant of this task may be the connection of single-mode and multimode fibers or emitters and photodetectors with fibers of various types. One of the methods of such matching is the creation of cascading fibers in which the lens fiber and several sections of the gradient fibers are integrated into a single-mode fiber. The subject of the study is the technology of elements of fiber-optic transmission systems. The objective of this work is to create components of fiber-optic communication lines that can improve the efficiency of inputting radiation from a source into an optical fiber, in particular single-mode. To achieve this goal, it is necessary to solve the following tasks: to consider the factors affecting the energy loss during generation and input of radiation from a source into an optical fiber, as well as to develop and implement a system of matching elements and give a sequence of actions for efficient input of radiation from a source into a single-mode fiber. Conclusion: during the work, the factors affecting the parameters of the radiation input into the fiber were investigated and the design of the resonant system for the formation of the electromagnetic radiation flux most suitable for input into the single-mode fiber was proposed, and a sequence of actions was proposed to determine the best relative position of the emitter and the fiber. The paper considers the problem and reasonable ways to increase the efficiency of radiation input into an optical fiber by using a resonator and studying the optimal conditions for the mutual arrangement of the fiber and the source. The proposed technical and technological implementation of the process makes it possible to introduce large power into the optoelectronic information transmission lines, which increases the efficiency of radiation input up to $20 \mathrm{~dB}$. Determining the accuracy of the location of the connecting plane in the matching devices and the relative position of the emitters and the optical fiber can reduce the loss in the connection to $0.1 \mathrm{~dB}$, transmit information with greater reliability over long distances without regeneration and maintain the operability of the fiber-optic system under mechanical, climatic and radiation factors.

Keywords : optical fiber; emitter; power; transmission efficiency. 